Bangladesh J. Sci. Ind. Res. 43(1), 67-76, 2008

\title{
Retention of Nitrate and Phosphate in Soil and their Subsequent Uptake by Plants
}

\author{
M.S. Islam ${ }^{\mathrm{a}}$, S.M. Ullah ${ }^{\mathrm{b}}$, T.H. Khan ${ }^{\mathrm{b}}$ and S.M. Imamul Huq \\ ${ }^{a}$ Department of Soil Science, University of Chittagong, Chittagong-4331 and ${ }^{b}$ Department of \\ Soil, Water and Environment, University of Dhaka, Dhaka-1000, Bangladesh.
}

\begin{abstract}
A laboratory based column leaching experiment was set up to study the retention of nitrate $\left(\mathrm{NO}_{3}{ }^{-}\right)$and phosphate $\left(\mathrm{PO}_{4}{ }^{3-}\right)$ in three Bangladesh soils (Ghatail, Tejgaon and Sonatola) and their subsequent uptake by plants (Ipomoea aquatica). The investigation showed that the higher the clay contents, the higher was the retention of $\mathrm{NO}_{3}{ }^{-}$and $\mathrm{PO}_{4}{ }^{3-}$ by the soils and the lesser was their transfer into the growing plants. Again the higher the $\mathrm{pH}$ values in soils, the lower was the retention of $\mathrm{NO}_{3}{ }^{-}$and $\mathrm{PO}_{4}{ }^{3-}$ elements retained in the soils and the higher was the transfer of the elements into the growing plant. Retention of nitrate and phosphate followed the order: Ghatail>Tejgaon> Sonatola while the transfer to plant was in the order Sonatola $>$ Tejgaon $>$ Ghatail.
\end{abstract}

Key Words: Nitrate, Phosphate, Retention, Leaching, Plant Uptake.

\section{Introduction}

For the first time in his entire cultural history, man is facing one of the most horrible ecological crises - the problem of pollution of his environment, which in the past was pure, virgin, undisturbed, uncontaminated, and basically quite hospitable for him (Miller, 1990). Waste disposal from various industries, municipal dumping in the urban areas and increased use of chemical fertilizers, pesticides and irrigation water are of great environmental concern (Singh and Kansal, 1985). The residues of fertilizers, pesticides and irrigation water in one hand, increased agricultural production; while, on the other hand, created adverse impact on soil and water bodies (Miller, 1990). Leaching of nitrate raises concern because of the supposed health hazard of nitrate levels in drinking water. High amount of nitrate in water and in food are of concern to humans and animals. The nitrate can cause problem of methemoglobinemia that result in the inability of the blood to transport oxygen $\left(\mathrm{O}_{2}\right)$. In 1996, WHO advocated for a strict standard for nitrate in drinking water and suggested a maximum allowable concentra- 
tion of only $45 \mathrm{mg} / \mathrm{l}$ as $\mathrm{NO}_{3}{ }^{-}$or $10 \mathrm{mg} / \mathrm{l}$ as $\mathrm{NO}_{3}-\mathrm{N}$. Currently 1.5 million tons of urea (675000 tons of $\mathrm{N}$ ) is used by the farmers annually. Of these $35 \%$ is utilized by the crops, $35 \%$ is lost in the atmosphere (Anderson, 1990) and the rest 30\% is supposed to be lost to drainage. The budgeting of phosphorus fertilizer has received less attention than nitrogen fertilizer. The high doses of phosphorus applied to freely draining soil immediately followed by heavy rainfall causes some phosphorus losses through volatilization and leaching processes (Anderson et al., 1991). Phosphorus fertilizer loss is heavily implicated in water course pollution and freshwater eutrophication. Thus once ecosystems are contaminated by these elements, they become potential threat for many years. Their accumulation reduces soil fertility, soil microbial activity, and plant growth, as well as, the quality of agricultural products (Miller, 1990). It is observed that when an element is applied to soil, some of it may be leached, some may be retained by the soil particles, some may be lost from the soil other than leaching loss, some may be incorporated by soil microorganisms or some may be taken up by plant. Keeping this in mind, the experiment was undertaken with the objectives- (i) to study the retention (sorption and/or chemically inactive) and leaching of nitrate phosphate, arsenic, cadmium and lead in soils with different clay contents and (ii) to evaluate the relationship between the retained elements and the amount taken up by growing plants.

\section{Materials and Methods}

Soil samples of three different series viz. Sonatola, Tejgaon and Ghatail series were collected from three different locations on a composite soil sampling basis as suggested by the Soil Survey Staff of the USDA (1951). All the three soils are moderately acidic in nature. Sonatola, Tejgaon and Ghatail series are developed on medium to moderately fine textured Brahmaputra Alluvium, deeply weathered Modhupur Clay and fine textured oldest Brahmaputra Alluvium respectively (Brammer, 1981). The samples were air- dried and sieved through a $2.0 \mathrm{~mm}$ sieve then mixed thoroughly and stored for the experiment and a portion of the samples was broken again and sieved through a $0.5 \mathrm{~mm}$ sieve for further analysis.

$\mathrm{pH}$, organic matter and particle size distribution of the soils were determined (Table I) following procedures described by Black (1995). Total nitrogen in soil was determined by alkali distillation on kjeldahl digest using a microdistillation apparatus as described by Jackson (1973). Plant nitrogen contents were also determined by micro-Kjeldahl methods following $\mathrm{H}_{2} \mathrm{SO}_{4}$ acid digestion and steam distillation with $40 \% \mathrm{NaOH}$ as described by Jackson (1962). Total phosphorus content of the soil was determined colorimetrically in the extract of $\mathrm{HNO}_{3}$ and $\mathrm{HCL}$ (1:3) digestion (Vdulfa, 1975) using a Chemo Visible Spectrophotometer after developing the yellow 
Table I. Some physio-chemical properties of the selected soil.

\begin{tabular}{l|l|l|l}
\hline \multicolumn{1}{c|}{ Parameters } & \multicolumn{1}{|c|}{ Sonatola } & Tejgaon & Ghatail \\
\hline Sand (\%) & 19 & 59 & 6 \\
Silt(\%) & 71 & 22 & 45 \\
Clay (\%) & 10 & 19 & 49 \\
Texturalclass & Silt loam & Sandy loan & Silt Clay \\
pH & 5.4 & 5.7 & 6.1 \\
Field capacity (\%) & 25.5 & 26.7 & 21.7 \\
Organic matter (\%) & 1.2 & 1.17 & 1.31 \\
Total N (\%) & 0.09 & 0.19 & 0.10 \\
Total P (\%) & 0.06 & 0.05 & 0.05 \\
Total K (\%) & 0.15 & 9.13 & 0.14 \\
Cation exchange & 10.8 & & 8.7 \\
capacity (meq/100g) & & & \\
\hline
\end{tabular}

Table II. Co-efficient of Correlation (r) between the clay content and the leaching, retention and uptake of nitrate and phosphate and between the solution concentration and the leaching, retention and uptake of nitrate and phosphate.

\begin{tabular}{l|l}
\hline & Co-efficient of Correlation (r) \\
\hline Clay content and leaching of nitrate & -0.61007 \\
Clay content and retention of nitrate & 0.862135 \\
Clay content and uptake of nitrate & -0.922 \\
Clay content and leaching of phosphate. & -0.81823 \\
Clay content and retention of phosphate. & 0.818887 \\
Clay content and uptake of phosphate. & -0.883 \\
Solution concentration and leaching of nitrate & 0.542197 \\
Solution concentration and retention of nitrate & 0.48614 \\
Solution concentration and uptake of nitrate & 0.393 \\
Solution concentration and leaching of phosphate & 0.520113 \\
Solution concentration and retention of phosphate & -0.49917 \\
Solution concentration and uptake of phosphate & 0.267 \\
\hline
\end{tabular}

color with Vanadomolybdate as described by Jackson (1973). The phosphorus of plant sample was extracted with ternary acid mixture
$\left(\mathrm{HNO}_{3}: \mathrm{H}_{2} \mathrm{SO}_{4}: \mathrm{HCLO}_{4}=5: 1: 2\right)$ digestion (IRRI, 1976). The phosphorus in the digest was also determined colorimetrically after 
developing the yellow color following methods as above.

\section{Experimental set -up}

To observe the retention and leaching of nitrate and phosphate through soil, Soil columns of different lengths were used. For the columns, PVC pipes of $5.08 \mathrm{~cm}$ diameter with different lengths were used. The lengths of the soil columns were chosen on the basis of soil texture and compaction. As such the lengths of the soil columns for Sonatola and Tejgaon soils each were $65 \mathrm{~cm}$ and for Ghatail soil it was $21 \mathrm{~cm}$. There was a $10 \mathrm{~cm}$ height of water table above the three soil columns. So, the total length of the PVC pipe for Sonatola and Tejgaon soils was $75 \mathrm{~cm}$ and $31 \mathrm{~cm}$ for Ghatail soil.The weight of the total soil in the column for both Sonatola and Tejgaon soil was $1.71 \mathrm{~kg}$ and $0.55 \mathrm{~kg}$ for Ghatail soil. Outlets were made at the bottom of the column to collect the leachate. Deionized water was used for control treatment and specified concentration of nitrate and phosphate in solution was used for the treatments. Three treatments 0,30 and 60 $\mathrm{kg} / \mathrm{ha}$ for nitrate and 0,15 and $30 \mathrm{~kg} / \mathrm{ha}$ for phosphate and a sum of 3, 4 and 4 liters of solution were added to Ghatail, Sonatola and Tejgaon soil, respectively.

The leachate was collected for 24 hours since beginning of the experiment. The concentration of the element in collected leachates for each element was determined and from this, the retention and leaching capacity of the respective soils were calculated. After completion of the leaching experiment, the soil of the plastic pipe was air- dried and transferred to small plastic pots for plant growth. Four seeds of "Gima Kalmi" (Ipomoea aquatica) were sown to each of the pots and allowed to germinate. The pot experiments were arranged in the nethouse in a completely randomized design. Positions of the pots were changed every alternative day to allow equal exposure of each of the pots to sunlight. Plants received only tap water every alternative day from seed sowing till plant harvest. Adequate plant protection measures were taken. The plants were allowed to grow for three weeks after the emergence of plants. Then the plants were harvested by uprooting them. The harvested roots were washed with deionized distilled water several times to remove the soil adhering to them and to free the ions from the roots free space. The aerial parts of plants were also washed. The collected plant samples were first air-dried and then oven-dried at $70^{\circ} \pm 5^{\circ} \mathrm{C}$ for 48 hours and the dry weights of plant sample were taken. The dry plant samples were then ground and passed through a $0.2 \mathrm{~mm}$ sieve for further analysis. After harvest, soil samples from each pot were also collected from the rhizosphere and prepared for further analysis as mentioned earlier. 


\section{Results and Discussion}

\section{Leaching}

Leaching of nitrate and phosphate in the selected soils as affected by clay content and solution concentrations are presented in the Figures 1 and 2. It was observed that the maximum amount of nitrate and phosphate was leached through Sonatola soil followed by Tejgaon soil, whereas the least amount was leached through Ghatail soil. The highest nitrate leaching was from Sonatola soil was at $60 \mathrm{~kg} \mathrm{NO}_{3}{ }^{-} /$ha treatment $(82 \%$ of the total nitrate present in the soil column) and the minimum was from the Ghatail soil at control ( $41 \%$ of the total nitrate present in the soil column). Phosphate leaching was as high as $75 \%$ of the total amount present in the soil column of Sonatola soil at $30 \mathrm{~kg}$ $\mathrm{PO}_{4}^{3-} /$ ha treatment and as low as $48 \%$ of the total amount from Ghatail soil at control. The leaching of nitrate and phosphate increased with increasing nitrate and phosphate concentration in solution. From the leaching study, it becomes apparent that the leaching was controlled by the clay fraction present in the soil. For all the two elements, the amount leached out was inversely related to the clay contents of the soils. On the basis of the clay content, the leaching was in the order: Ghatail> Tejgaon >Sonatola. For the indivisual elements, the leaching order: Sonatola $>$ Tejgaon $>$ Ghatail, respectively for nitrate and phosphate. The observation agrees well with the findings of Greenland and Hayes (1981) for nitrate. They observed that the leaching losses of nitrate are generally higher from coarse textured sandy soils than from fine textured clay soils. According to Brady (1990), phosphate fixation tends to be more pronounced in clays than in the course textured ones. Correlation between the clay content and the leaching of nitrate and phosphate were compared. The "r" values were -0.61007 and -0.81823 for nitrate and phosphate, respectively. It needs to be mentioned here that the clay contents of the three soils were-49, 19 and 10\% in Ghatail , Tejgaon and Sonatola soil, respectively.

The solution concentration of nitrate and phosphate also affected their leaching from the soil. It was observed that the leaching of nitrate and phosphate increased with increase in their concentrations in the solution. The results agree well with the observation made by Conway and Pretty (1991) for nitrate. According to them, nitrate leaching from high doses of applied nitrate was significantly higher than that of the low doses applied. According to Greenland and Hayes (1981), phosphate leaching from high doses of applied phosphate was significantly higher than that of the low doses applied. The "r" values were 0.542197 and 0.520113 for nitrate and phosphate, respectively.

Regression equations were calculated using the values of clay content of the soils, the solution concentrations and the amount of each of the elements in the leachate where 

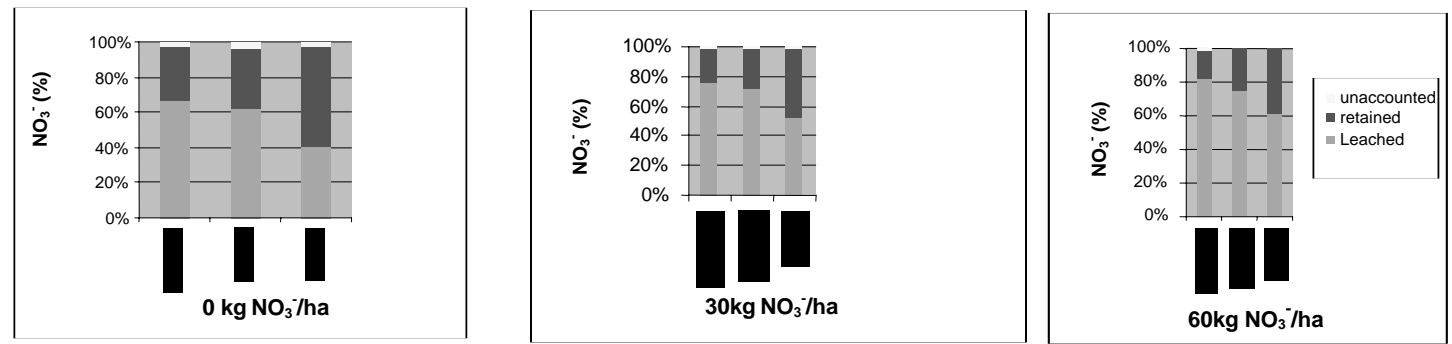

Treatment $\mathrm{kg} \mathrm{NO}_{2}^{-} / \mathrm{ha}$

(a)
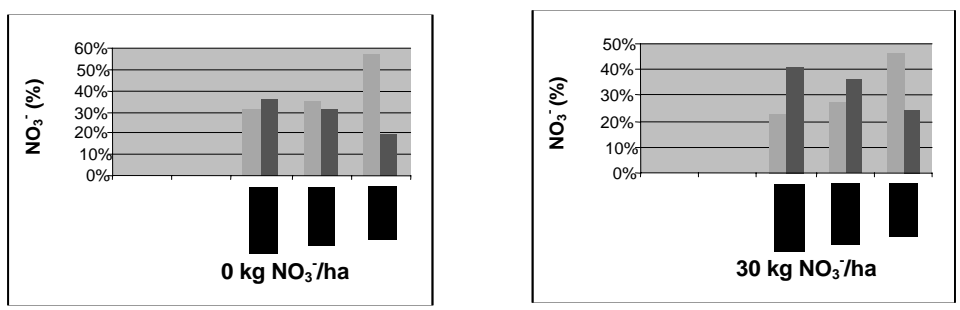

Treatment $\mathrm{kg} \mathrm{NO}_{3}^{-} /$ha

(b)

Fig: 1. (a) Percent of applied nitrate leached through soil column, retained and unaccounted for at different reatments, (b) percent of retained nitrate taken up by the growing plant
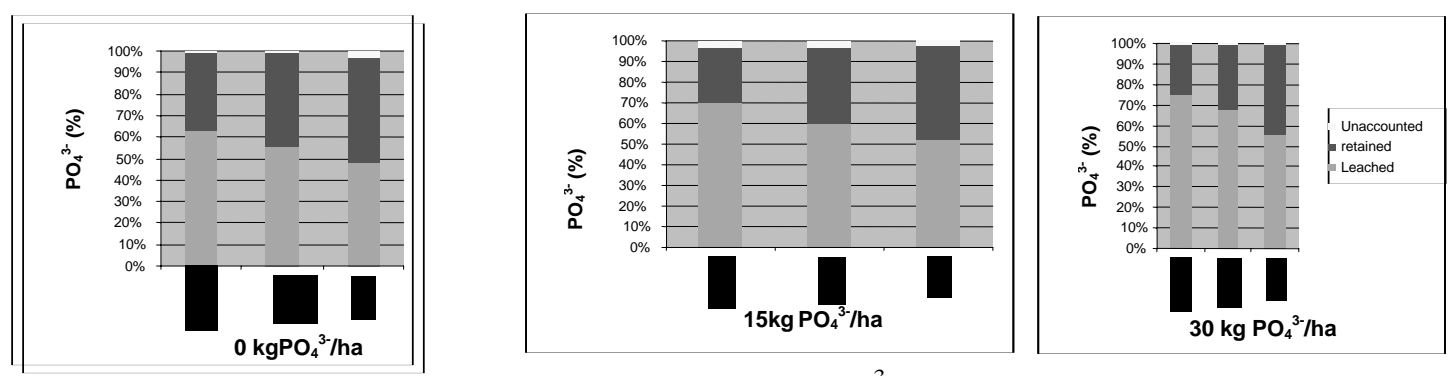

Treatment $\mathrm{kg} \mathrm{PO}_{4}^{3-} / \mathrm{ha}$

(a)
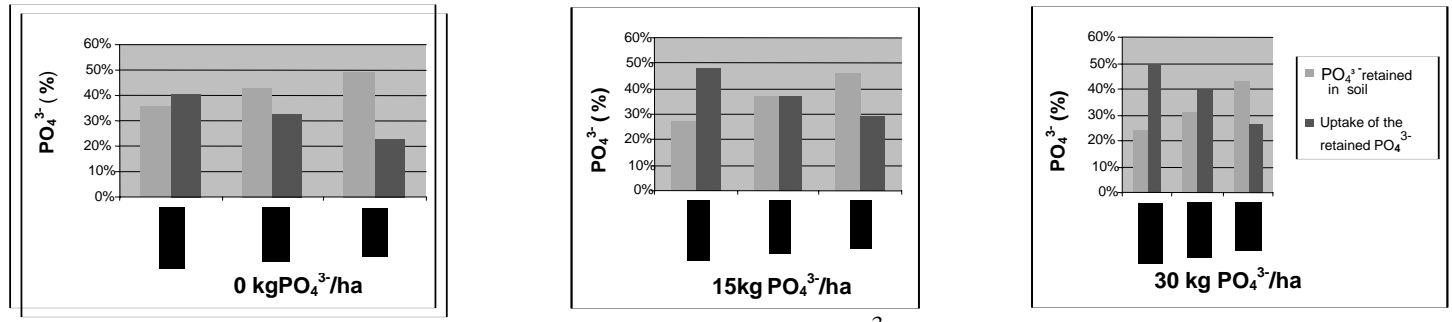

Treatment $\mathrm{kg} \mathrm{PO}_{4}^{3-} / \mathrm{ha}$

(b)

Fig 2. (a) Percent of applied phosphate leached through soil column, retained and unaccounted for at different treatments. (b) Percent of retained phosphate taken up by growing plant 
clay content of the soil and the solution concentration were the independent variable- $\mathrm{X}_{1}$ and $\mathrm{X}_{2}$, the amount of the element in the leachate was the dependable variable Y. The equations were: $\mathrm{Y}=$ 93.011-0.61007 $\mathrm{X}_{1}{ }^{+}$ $0.542197 \mathrm{X}_{2}$ (for nitrate) and $\mathrm{Y}=66.238$ $0.411 \mathrm{X}_{1}+0.356 \mathrm{X}_{2}$ (for phosphate). The values of $\mathrm{R}^{2}$ were 0.981 and 0.94 .

\section{Retention}

The retention of nitrate and phosphate in all the soils was investigated. The results were shown in the Figures 1 and 2. It was observed that the maximum amount of nitrate and phosphate was retained in Ghatail soil followed by Tejgaon soil with the least in Sonatola soil. The retention of nitrate was at the maximum in Ghatail soil with $57 \%$ of the applied nitrate retained at control. While the least was in Sonatola soil with $17 \%$ retained at $60 \mathrm{~kg} \mathrm{NO}_{3}^{-}$/ha. The maximum $\mathrm{PO}_{4}^{3-}$ that was retained in Ghatail soil at control, was $49 \%$ and the minimum was $24 \%$ in Sonatola soil at control condition. The higher the clay contents in soil, the higher were the elements retained in the soils. Ghatail soil containing $49 \%$ clay which was more than either Tejgaon (19\%) or Sonatola soil (10\%) retained the maximum amount of each of the elements. The retention of nitrate and phosphate followed the order: Ghatail> Tejgaon> Sonatola. The results agree well with the observations made by Greenland and Hays (1981) for nitrate and Brady (1990) for phosphate. According to
Greenland and Hayes (1981), the leaching losses of nitrate are generally higher from coarse textured sandy soils than from fine textured clay soils. This means that the rate of retention of nitrate is higher in Ghatail soil than the caurse textured Sonatola soil. According to Brady (1990), phosphate fixation tends to be more pronounced in clays than in the course textured ones. Correlation between the clay content and the amount of nitrate and phosphate retained by the soil were calculated. The values of "r" were 0.862135 and 0.818887 for nitrate and phosphate, respectively. The clay content of the soils and the amount of retained elements were positively correlated signifying the fact that a clayey soil will retain more of the elements.

Application of nitrate and phosphate also affected the retention of each element in soils. It was observed that the retention of nitrate and phosphate showed a decrease with increase in their solution concentration. The maximum retention of nitrate and phosphate was observed at control whereas the retention was minimum at $60 \mathrm{~kg} / \mathrm{ha}$ for nitrate and $30 \mathrm{~kg} / \mathrm{ha}$ for phosphate. According to Conway and Pretty (1991), nitrate leaching from high doses of applied nitrate was significantly higher than that of the low doses applied. Again, according to Greenland and Hayes (1981), phosphate leaching from high doses of applied phosphate was significantly higher than from the low doses applied. Correlation between the 
treatment concentration and the adsorption of nitrate and phosphate by soils was calculated and the values of " $r$ " were -0.48614 for nitrate and -0.49917 for phosphate, respectively.

Regression coefficient was calculated using the values obtained from regression equations of clay content of the soils, the solution concentrations and the amount of each of the elements retained, where clay content of the soil and the solution concentration were the independent variable- $\mathrm{X}_{1}$ and $\mathrm{X}_{2}$, the amount of the element retained was the dependable variable $\mathrm{Y}$. The equations were: $\mathrm{Y}=$ $24.528+0.608 \mathrm{X}_{1}-0.233 \mathrm{X}_{2}$ (for nitrate) and $\mathrm{Y}=31.89+0.402 \mathrm{X}_{1}-0.333 \mathrm{X}_{2}$ (for phosphate). The values of $R^{2}$ were 0.98 and 0.92 for nitrate and phosphate, respectively.

\section{Uptake of Nitrate and Phosphate by the plant}

The amount of the retained nitrate and phosphate taken - up by the growing plant (Ipomoea aquatica) from the soils are presented in the Figures 1 and 2. It was observed that the maximum amount of nitrate and phosphate was accumulated from Sonatola soil followed by Tejgaon soil, whereas the minimum was from the Ghatail soil. The plant accumulated as high as $43 \%$ of the retained nitrate from Sonatola soil at $60 \mathrm{~kg} \mathrm{NO}_{3}^{-}$-/ha treated soil, whereas the minimum (19\%) of the retained nitrate was accumulated from Ghatail soil at control. In case of phosphate, $49 \%$ of the retained phosphate was accumulated from Sonatola soil at $30 \mathrm{~kg}$
$\mathrm{PO}_{4}{ }^{3-} /$ ha treated soil and the minimum (23\%) of the retained phosphate was accumulated from Ghatail soil at control. Clay was found to have a direct relation with the uptake of all the elements into plants. Because of high clay content in Ghatail soil, most of the nitrate and phosphate became immobile in this soil that caused a low bioavailability of the elements. Tejgaon soil has relatively higher clay content than that of Sonatola soil and consequently, the uptake was lower from Tejgaon soil compared to that from Sonatola soil. According to Honney (1989), the uptake of ammonium and to a lesser extent nitrate by plant affected by clay content of the soil. Again, according to Brady (1990), soils with higher clay contents tend to fix phosphorus in forms not readily available to the crop plants. Correlation between the clay content and the uptake of nitrate and phosphate was computed. The values of "r" were -0.922 and -0.883 for nitrate and phosphate, respectively. The negative values of " $\mathrm{r}$ " are indicative of the negative influence on bioavailability of these elements in soils.

The treatments seemed to have an effect on the subsequent uptake of the elements by the crop. Again, the soil properties like the $\mathrm{pH}$ and clay contents appeared to have played an important role in this regard too. The uptake of nitrate from all the three soils increased with increasing nitrate concentration in the soil. According to Greenland and Hayes (1981), the increasing amount of nitrate concentrations in soil enhances its uptake by 
plant. The uptake of phosphate by plant also increased with increasing its concentration in soil. According to Conway and Pretty (1991), the uptake of phosphate increases to a lesser extent with increasing its concentration in solution. The uptake of phosphate from Sonatola and Tejgaon soil increased with increasing phosphate concentration , whereas from Ghatail soil, the level of phosphate uptake increased from control to treatment of $15 \mathrm{~kg} / \mathrm{ha}$ but it slightly decreased at higher treatment (30kg $\mathrm{PO}_{4}{ }^{3-} / \mathrm{ha}$ ). Correlation coefficient (r) between the uptake and the applied concentration of nitrate and phosphate were 0.393 and 0.267 respectively, showing a weak positive correlation.

Regression equations between the uptake of the elements by Kalmi (Y) and the clay content of the soils $\left(\mathrm{X}_{1}\right)$, were obtained from the applied concentrations of nitrate and phosphate $\left(\mathrm{X}_{2}\right)$.The equations were : $\mathrm{Y}=39.592-$ $0.363 \mathrm{X}_{1}+0.11 \mathrm{X}_{2}$ (for nitrate) and $\mathrm{Y}=$ 45.509-0.47 $X_{1}+0.189 X_{2}$ (for phosphate). The values of $\mathrm{R}^{2}$ were 0.929 and 0.892 for nitrate and phosphate, respectively.

\section{Conclusion}

The results of the present investigation clearly demonstrate the possible fates of nitrate and phosphate and the aftereffect of these elements on the plants. Again, it is apparent from this experiments that the clay content of a soil will have a positive role to play against contamination of the groundwater by controlling their leaching, the adverse effect of the addition of these elements to soil and their subsequent entry into the food chain could also be contained in heavy soils. The higher this concentration in soils, the greater is the risk to contaminate both the groundwater aquifers as well as the food chain. However, further research on the extent of pollution by environmental pollutants, various underlying processes that can bring about toxic effects on different crop species and their control will be more useful.

\section{References}

Anderson, A and G. Siman. (1991) Levels of Cd and some other trace elements in soils and crops as influenced by lime and fertilizer level. Acta - Agriculture - Scandinavica. 41: 3 - 11.

Black. C.A. (1995) Methods of Soil Analysis. Part 1. Am. Soc. Agro., Madison, Wisconsin, U. S. A. 14-96.

Brady. N.C. (1990) The Nature and Properties of Soils (10th ed.). Macmillan Publishing Company, New York, U. S. A. 530-44.

Brammer. H. (1981) Reconnaissance Soil Survey of Dhaka District. Revised Edition, Department of Soil Survey. 6-19.

Conway, G.R. and Pretty J.N. (1991) Unwelcome harvest agriculture and pollution, Earthcan Publications Ltd.445-504.

Greenland, D.J. and Hayes M.H.B. (1981) The 
Chemistry of Soil Processes. John Wiley and Sons Ltd. 593-619.

Honney. R.D. Nitrogen in crop production. Amer. Soc. Agron., Crop Sci. Soc. Amer., Soil Sci. Soc. Amer. Madison, WL. (1989) 19-35.

IRRI. (1976) Laboratory manual for physiological studies of rice. (3rd ed.).Suchi Y. Y., D. A. Forno, J. H. Cock and K. A. Gomez (eds.). The International Rice Research Institute, Loss Banos, Philippines. 12-23.

Jackson. M.L. (1962) Soil Chemical Analysis. Prentic Hall Inc. Englewood Cliffs. N. J., U.S.A. $14-98$.

Jackson. M.L. (1973) Soil Chemical Analysis. Prentic Hall of India Pvt. Ltd., New Delhi. 9-82.

Miller, R.W. and Donahue R.L. (1990) SOILS: An Introduction to Soils and Plant Growth. (6th ed.) Prentic - Hall, Inc., Englewood Cliffs, New Jersey, U. S. A. 537-74.
Singh J and Kansal B. D. (1985) Amount of heavy metals in the waste water of different towns of Punjab and its evaluation for irrigation. J. Res. Punjab Agric. Univ. 22 : 17 $-24$.

USDA. (1951) Soil survey manual, handbook. 80: 503.

Vdlufa, S., (1975) Konings Wasserauszug (Vorschlagen-des). Landwirtschaftliches Chemischen Institut Der Universitat, Bonn. Beurteilung der Siedlungsabfalkompsote (SAK) als Produkdionsmitted der Landw irtscha ftliches. 4 : 35-68.

WHO. (1996) Guideline for Drinking Water Quality. (21st ed.). 2: 158 - 62

Received : March, 19, 2007;

Accepted : October 23, 2007 